\title{
A prospective, case controlled study of the natural history of diabetic retinopathy and maculopathy after uncomplicated phacoemulsification cataract surgery in patients with type 2 diabetes
}

\author{
D Squirrell, R Bhola, J Bush, S Winder, JF Talbot
}

Br J Ophthalmol 2002;86:565-571

See end of article for authors' affiliations

Correspondence to: Mr S Winder, Department of Ophthalmology, Royal Hallamshire Hospital Sheffield S10 2RX, UK; steve@winder 100.fsnet.co.uk

Accepted for publication 9 January 2002

\begin{abstract}
Aim: To determine if uncomplicated phacoemulsification cataract surgery is associated with an accelerated rate of progression of diabetic retinopathy or maculopathy postoperatively.

Methods: A prospective trial of 50 type 2 diabetics undergoing monocular phacoemulsification cataract surgery by a single consultant surgeon. The grade of diabetic retinopathy and diabetic maculopathy in the operated and non-operated fellow eye was assessed preoperatively and for 12 months postoperatively.

Results: Overall, retinopathy progression was observed in 11 patients. In seven the retinopathy progressed in both eyes, in three it progressed in the operated eye alone, and in one it progressed in the fellow eye alone. Macular oedema was observed in 13 eyes postoperatively. Four had transient pseudophakic cystoid macular oedema and nine true diabetic maculopathy. Where maculopathy progressed it did so symmetrically in five patients, it progressed in the operated eye alone in four patients, and the fellow eye alone in two patients. There was no significant difference in the number of operated and fellow eyes whose retinopathy or maculopathy progressed postoperatively. In both the operated $(\mathrm{OE})$ and non-operated (NoE) eyes retinopathy progression was associated with a higher mean $\mathrm{HbA}_{1} \mathrm{C}(\mathrm{OE} \mathrm{p}=0.003 ; \mathrm{NoE} p=0.001)$ and insulin treatment $(\mathrm{OE} \mathrm{p}=0.008, \mathrm{NoE} p=0.04)$.

Conclusion: Uncomplicated phacoemulsification cataract surgery does not cause acceleration of diabetic retinopathy postoperatively and any progression that is observed probably represents the natural history of the disease. Although macular oedema is common after cataract surgery it may follow a benign course and in many patients the development of clinically significant macular oedema postoperatively probably represents natural disease progression rather than being a direct effect of surgery.
\end{abstract}

E pidemiological data suggest that $3 \%$ of the UK's population has diabetes mellitus and a further $2 \%$ may be currently undiagnosed. Cataract is a well recognised complication of diabetes and it has been estimated that up to $20 \%$ of all cataract surgery is performed on diabetic patients. ${ }^{1}$ The 1997 guidelines of the Royal College of Ophthalmologists state that all forms of diabetic retinopathy may become more severe following cataract surgery. ${ }^{2}$ However, much of the evidence upon which this statement was based came from retrospective case note reviews of patients undergoing extracapsular cataract surgery. ${ }^{34}$ When the few controlled prospective trials that have been conducted in this area are reviewed the evidence in support of this statement becomes less convincing. ${ }^{56}$

We wished to investigate whether uncomplicated phacoemulsification cataract surgery was responsible for an acceleration in the rate of progression of diabetic retinopathy and diabetic maculopathy. We report the findings of a prospective study in which we investigate the influence of monocular cataract surgery on diabetic retinopathy and diabetic maculopathy using the non-operated fellow eye as a control.

\section{PATIENTS AND METHODS}

All patients with type 2 diabetes who underwent monocular cataract surgery by one consultant surgeon in February and March 1999 were prospectively approached and invited to participate in the study. Exclusion criteria included a history of cataract surgery in the fellow eye within the previous 12 months, or a level of lens opacity in the fellow eye which was likely to preclude adequate fundal examination for the duration of the study. Patients were also excluded from the study if the retinopathy in the two eyes was deemed to be markedly asymmetrical at the preoperative fundal examination (defined as a difference of greater than one level on the Early Treatment Diabetic Retinopathy Study (ETDRS) grading system $^{7}$ (Table 1)). Based on these criteria 58 patients were deemed eligible to enter into the study, of whom 50 consented to participate. Any patient who required or requested cataract surgery in the fellow eye was listed in accordance with existing departmental protocols. These patients remained under review and were included within the main retinopathy/ maculopathy progression analysis until the second eye surgery was performed. Thereafter the data pertaining to these patients were analysed separately. All patients underwent routine phacoemulsification cataract surgery under subTenon's anaesthesia. There were no operative complications in the group of patients under study.

\section{Demographic data collection}

All patients were assessed 1 week before their cataract surgery and a full medical and ocular history taken. The patients' age, the presence of coexisting hypertension, time elapsed since diagnosis of diabetes, and their current treatment regimen was recorded. All patients had their preoperative glycaemic control assessed by $\mathrm{HbA}_{1} \mathrm{C}$ measurement.

\section{Examination procedure}

All patients underwent a thorough fundus examination, which included macular contact lens examination, l week 


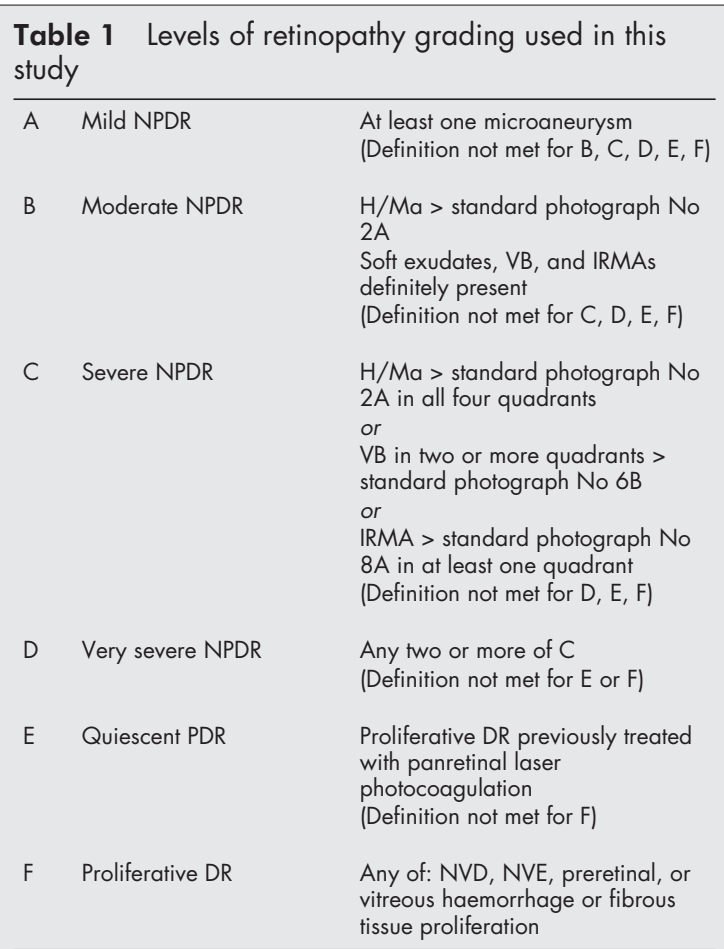

NPDR = non-proliferative diabetic retinopathy, $\mathrm{H} / \mathrm{Ma}=$ haemorrhage/microaneurysm, VB = venous beading, IRMA = intraretinal microvascular abnormalities, PDR = proliferative diabetic retinopathy.

From ETDRS.

before surgery and the status of the retinopathy and maculopathy in both eyes was noted. Where the view of the retina was obscured by the lens opacity the preoperative retinopathy and maculopathy status was assumed to be that recorded on the first postoperative day. A patient's diabetic retinopathy was graded using the ETDRS grading system ${ }^{7}$ (Table 1). Clinically significant macular oedema (CSMO) was defined according to ETDRS criteria. ${ }^{8}$

All patients were examined postoperatively at day 1 , and then re-examined at 1, 3, 6, and 12 months after surgery. At each review the Snellen visual acuity and the retinopathy and maculopathy status in both eyes was recorded. Further follow up was arranged as clinical need dictated. Panretinal photocoagulation (PRP) was performed for all patients who developed proliferative diabetic retinopathy in accordance with established guidelines. All patients who developed either new or recurrent macular oedema within 3 months of surgery (as defined as retinal thickening evident with macular contact lens examination), underwent fluorescein angiography. The macular oedema was classified as pseudophakic cystoid macular oedema if the fluorescein angiogram revealed a typical petaloid pattern of foveal hyperfluorescence." Patients whose angiogram revealed a more diffuse pattern of foveal hyperfluoresence were classified as new/recurrent diabetic maculopathy. Regardless of the presumed aetiology of the postoperative macular oedema all eyes were treated with medical therapy alone for 3 months (topical and/or regional steroids). After 3 months had elapsed any persisting macular oedema was then treated with either focal or grid laser photocoagulation treatment as defined by the ETDRS. ${ }^{8}$ Any patient who developed CSMO more than 3 months after surgery was considered to have new/recurrent diabetic maculopathy and was therefore treated with laser photocoagulation as in the ETDRS guidelines as soon as was practically possible. Any patient whose lens opacity precluded adequate fundus examination preoperatively and was subsequently found to have

\section{Table 2 Demographic data}

\begin{tabular}{ll}
\hline Male/female & $27 / 23$ \\
Age in years (mean) & 73 (range 59-88) \\
Duration of diabetes in years (mean) & 13 (range 2-38) \\
$\begin{array}{l}\text { Pre-existing hypertension } \\
\text { Preoperative mean } \mathrm{HbA}_{1} \mathrm{C}\end{array}$ & 29 patients $(58 \%)$ \\
$\begin{array}{l}\text { Treatment regimen } \\
\text { insulin requiring }\end{array}$ & $8.5 \%$ (range 5.8-11.1\%) \\
tablet controlled & 20 patients \\
$\quad$ diet controlled & 25 patients \\
Preoperative visual acuity & 5 patients \\
$>6 / 12$ & \\
$6 / 12-6 / 18$ & No patients \\
$6 / 24-6 / 36$ & 14 patients \\
$\leqslant 6 / 60$ & 14 patients \\
\hline
\end{tabular}

macular oedema with associated exudates at the day 1 postoperative examination was assumed, for the purposes of data collection and analysis, to have had CSMO at the time of surgery. Such patients were treated with either focal or grid laser photocoagulation treatment as defined by the ETDRS as soon was practically possible.

\section{Statistical analysis}

The McNemar test for paired data was used to compare the number of operated and fellow eyes that had progressive retinopathy and maculopathy. Student's paired $t$ test was used to compare the mean $\mathrm{HbA}_{1} \mathrm{C}$ and mean duration of diabetes in those patients whose retinopathy or maculopathy progressed in the operated eye, with those patients whose retinopathy or maculopathy did not progress in the operated eye. This calculation was repeated for the cohort of non-operated eyes. The McNemar test for paired data was used to analyse whether retinopathy or maculopathy progression was more common in those patients who either required insulin or had pre-existing hypertension compared to those who did not. This analysis was performed within the cohort of operated eyes and then repeated for the cohort of non-operated eyes. Logistic regression analysis was then performed to study the relation between retinopathy and maculopathy progression in the operated and then the non-operated eyes and the following preoperative factors: mean $\mathrm{HbA}_{1} \mathrm{C}$, the duration of diabetes, the presence of pre-existing hypertension, and insulin treatment.

\section{Power calculation}

A review of the data available at the time this study was designed suggested that $27 \%$ to $41 \%$ of operated eyes and $0 \%-27 \%$ of non-operated eyes were likely to experience retinopathy progression after cataract surgery. ${ }^{3-6} 0^{10-15}$ The increased risk of retinopathy progression after cataract surgery in these studies ranged from $-5 \%$ to over $800 \%$ with a median of $300 \%$. For the purposes of our power calculation we therefore estimated that cataract surgery was associated with a threefold $(300 \%)$ risk of retinopathy progression in the operated eye compared to the non-operated eye. We calculated that 50 patients would have to be recruited to detect this anticipated $300 \%$ increase in risk with a power of $80 \%$.

\section{RESULTS}

\section{Patient characteristics and preoperative data}

Forty four patients completed 12 months of follow up and four of the remainder completed 6 months of follow up. Two patients died during the study period and two patients were lost to follow up. Eighteen fellow eyes were pseudophakic. Two patients underwent surgery to the fellow eye during the study; one after 6 months the other 8 months. The preoperative demographic data are listed in Table 2. The mean age of 
Table 3 Status of individual patients diabetic retinopathy at the time of surgery

\begin{tabular}{llllllcc}
\hline & None & Mild NPDR & Moderate NPDR & Severe NPDR & Very severe NPDR Treated PDR & PDR \\
\hline Operated eye & 9 & 10 & 18 & 2 & 2 & 8 & 1 \\
Fellow eye & 9 & 10 & 19 & 1 & 1 & 10 & 0 \\
\hline
\end{tabular}

Table 4 Status of individual patients diabetic maculopathy at the time of surgery

\begin{tabular}{lllll}
\hline & Dry & $\begin{array}{l}\text { Macular oedema, but } \\
\text { not CSMO }\end{array}$ & CSMO & $\begin{array}{l}\text { Treated } \\
\text { CSMO }\end{array}$ \\
\hline $\begin{array}{l}\text { Operated eye } \\
\text { Fellow eye }\end{array}$ & 24 & 5 & 1 & 20 \\
\hline \multicolumn{2}{l}{ CSMO = clinically significant macular oedema as defined by ETDRS. } & 2 & 19 \\
\hline
\end{tabular}

patients undergoing cataract surgery in this study was 73 years. At their preoperative assessment 20 patients (40\%) were receiving insulin, $25(50 \%)$ were receiving oral hypoglycaemics, and the remaining five $(10 \%)$ were controlled on diet alone. At the time of cataract surgery 29 patients (58\%) were hypertensive on medication. The median preoperative Snellen visual acuity was 6/36 (range 6/12 to "hand movements").

The preoperative status of patient's diabetic retinopathy in both the operated and fellow eyes is listed in Table 3. Eight of the operated eyes had previously undergone PRP for proliferative retinopathy before cataract surgery compared to 10 of the fellow eyes. One patient had active proliferative retinopathy which was not visible until the first postoperative day. This patient was treated with a full PRP without any further sequelae throughout the remainder of the study period. Four operated eyes and two fellow eyes had high risk nonproliferative retinopathy (graded severe or very severe by ETDRS criteria) identified at the time of surgery. Nine patients had no diabetic retinopathy in either their operated or fellow eye before cataract surgery. The remainder in both groups $(28$ operated eyes and 29 fellow) had low risk non-proliferative retinopathy (graded mild or moderate by ETDRS criteria).

The preoperative status of patients' diabetic maculopathy in both the operated and fellow eyes is listed in Table 4. Twenty operated eyes and 19 fellow eyes had clinically significant macula oedema (CSMO) which had been previously treated before cataract surgery. One operated eye was found to have CSMO which was not visible until the first postoperative day. This patient was treated with a macular grid immediately after surgery but required further laser treatment 6 months later. Two fellow eyes had CSMO identified at the preoperative assessment which was treated immediately according to the ETDRS protocols. Five eyes in both groups had evidence of retinal thickening before surgery that did not meet ETDRS criteria for CSMO; 24 eyes in both groups had no evidence of macular oedema.

\section{Postoperative visual acuity}

Visual acuity improved by two lines or more in 37 (74\%) patients and 31 patients (63\%) had a postoperative visual acuity of 6/12 or better. Of the 10 patients in our study who had a postoperative visual acuity of $6 / 36$ or worse, four had ischaemic maculopathy, three had persistent macular oedema, two developed disciform age related maculopathy, and one sustained an ischaemic branch retinal vein occlusion.

\section{Progression of diabetic retinopathy postoperatively}

Retinopathy progression was observed in 10 operated eyes $(20 \%)$ and eight fellow eyes (16\%) during the study period. There was no significant difference in the number of operated and fellow eyes that had evidence of progressive retinopathy

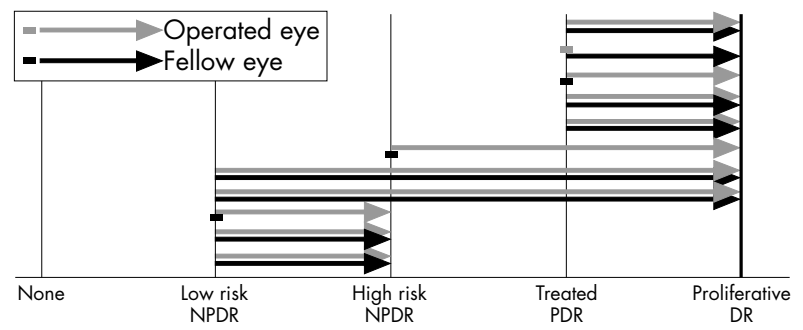

Figure 1 Graphic representation of those patients whose diabetic retinopathy progressed.

$(p=0.63)$. The extent of the progression that occurred in all patients who experienced retinopathy progression is illustrated in Figure 1. Overall, the retinopathy progressed in 11 patients after monocular cataract surgery and in seven patients the diabetic retinopathy progressed equally in both the operated and fellow eye. The diabetic retinopathy progressed in the operated eye alone in just three patients and progressed in the fellow eye alone in just one patient (Fig l). Where retinopathy progressed in the operated eye alone it did so within 3 months of surgery. Where the retinopathy progressed in the fellow eye alone it also did so within 3 months of surgery. Of the seven patients whose retinopathy progressed equally over the study period it did so at a symmetrical rate in four patients. In two patients the retinopathy progressed more rapidly in the operated eye (within 3 months in the operated eye and 6 months in the fellow eye) and in the remaining patient it progressed more rapidly in the fellow eye (within 3 months in the fellow eye and 6 months in the operated eye). The two patients who underwent second eye surgery during the study had mild nonproliferative diabetic retinopathy in both the operated and fellow eyes. No retinopathy progression was observed in either eye for the duration of the study period.

In both the operated (OE) and non-operated (NoE) cohorts, Student's paired $t$ test revealed a higher mean $\mathrm{HbA}_{1} \mathrm{C}$ in those patients whose retinopathy progressed compared to those patients whose retinopathy did not progress $(\mathrm{OE} p=0.003$, NoE $p=0.001$ ) (Table 5). There was no significant difference in the duration of diabetes in those patients whose retinopathy progressed and those whose retinopathy did not progress in either cohort (Table 5). The McNemar test revealed that a significantly greater number of patients on insulin experienced retinopathy progression in both cohorts of eyes postoperatively compared to those patients not requiring insulin (OE $p=0.008$, NoE $p=0.04$ ) (Table 5). There was no significant difference in the number of patients who had pre-existing hypertension and retinopathy progression in either the operated or non-operated eyes (Table 5). 
Table 5 Analysis of diabetic retinopathy progression with respect to the individual preoperative factors

\begin{tabular}{|c|c|c|c|c|c|c|}
\hline & \multicolumn{3}{|l|}{ Operated eye } & \multicolumn{3}{|c|}{ Non-operated eye } \\
\hline & $\begin{array}{l}\text { DR progressed } \\
(\mathrm{n}=10)\end{array}$ & DR static $(n=40)$ & $\mathrm{p}$ Value & $\begin{array}{l}\text { DR progressed } \\
(\mathrm{n}=8)\end{array}$ & DR static $(n=42)$ & p Value \\
\hline Preoperative mean $\mathrm{HbA}_{1} \mathrm{C}$ (SD) & $9.5 \%(1.1 \%)$ & $7.9 \%(1.4 \%)$ & 0.003 & $9.8 \%(1.2 \%)$ & $8.0 \%(1.4 \%)$ & 0.001 \\
\hline Duration of DM (years) (SD) & $15.9(9.6)$ & $13.3(9.5)$ & 0.42 & $12.8(5.7)$ & $13.9(10.1)$ & 0.74 \\
\hline Pre-existing hypertension $(\mathrm{n}=29)$ & $6 / 10$ & $23 / 40$ & 0.85 & $4 / 8$ & $25 / 42$ & 0.87 \\
\hline Insulin treatment $(n=20)$ & $8 / 10$ & $12 / 40$ & 0.008 & $6 / 8$ & $14 / 42$ & 0.04 \\
\hline
\end{tabular}

\begin{tabular}{|c|c|c|c|c|}
\hline \multirow[b]{2}{*}{ Variable } & \multicolumn{2}{|l|}{ Operated eye } & \multicolumn{2}{|l|}{ Non-operated eye } \\
\hline & Odds ratio $(95 \% \mathrm{CI})$ & $\mathrm{p}$ Value & Odds ratio $(95 \% \mathrm{Cl})$ & $\mathrm{p}$ Value \\
\hline Preoperative mean $\mathrm{HbA}_{1} \mathrm{C}$ & 2.9 (1.3 to 6.7$)$ & 0.01 & 7.5 (1.6 to 35.8$)$ & 0.01 \\
\hline Duration of DM & $0.9(0.8$ to 1.0$)$ & 0.51 & 0.8 (0.7 to 1.0$)$ & 0.08 \\
\hline Pre-existing hypertension & 2.8 (0.4 to 19.3) & 0.28 & $6.0(0.4$ to 94.0$)$ & 0.20 \\
\hline Insulin treatment & 6.7 (0.7 to 61.3$)$ & 0.09 & 15.8 (0.7 to 68.0) & 0.08 \\
\hline
\end{tabular}

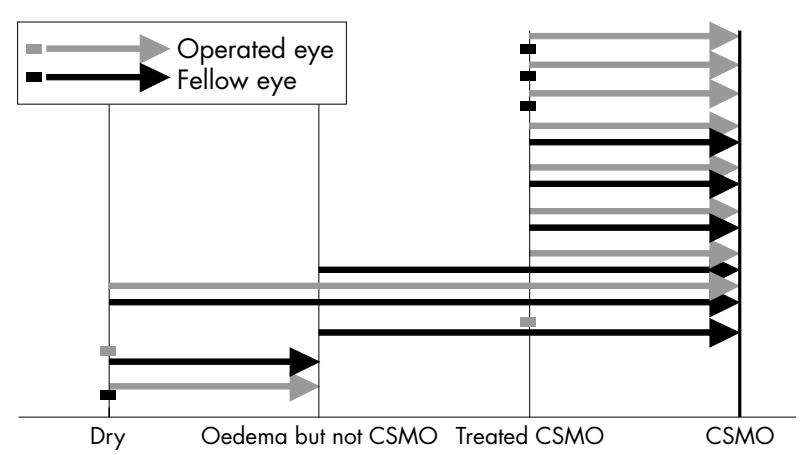

Figure 2 Graphic representation of those patients whose diabetic retinopathy progressed.

Logistic regression analysis revealed a significant relation between the level of the preoperative $\mathrm{HbA}_{1} \mathrm{C}$ and progression of retinopathy in both the operated $(p=0.01)$ and nonoperated $(p=0.01)$ eyes (Table 6$)$. Logistic regression analysis failed to reveal a statistically significant relation between any of the other preoperative factors and the progression of the diabetic retinopathy in either cohort of eyes postoperatively (Table 6).

\section{Progression of diabetic maculopathy postoperatively}

Overall, 13 eyes in the operated group were found to have retinal thickening of the central macula after cataract surgery. Of these 13 eyes, two had no preoperative diabetic maculopathy and fluorescein angiography revealed the typical petalloid hyperfluorescence that is classically associated with "Irvine
Gass" pseudophakic cystoid maculopathy. These two eyes were therefore managed as typical pseudophakic cystoid maculopathy and both improved with medical management within 3 months of treatment. The remaining 11 eyes all had previously treated CSMO which was deemed quiescent before surgery (no retinal thickening noted). Postoperative fluorescein angiography was inconclusive and these patients were therefore initially all labelled as experiencing postoperative exacerbation of their diabetic maculopathy. Of these, two eyes improved with medical treatment within the first 6 months of surgery exhibiting an improvement in visual acuity and decreased retinal thickening. For the purposes of data analysis these two patients were therefore finally classified as having developed atypical pseudophakic cystoid maculopathy rather than progressive diabetic maculopathy. Progressive diabetic macular oedema not responding to medical treatment was therefore observed in only nine operated eyes after surgery.

The extent of the progression that occurred in all patients who experienced maculopathy progression is illustrated in Figure 2. Overall, progressive diabetic maculopathy occurred in 11 patients. In five patients the diabetic maculopathy progressed in both the operated and fellow eye. In four it progressed in the operated eye alone and in two it progressed in the non-operated eye alone (Fig 2). There was no significant difference in the number of operated and fellow eyes that had evidence of progressive maculopathy $(p=0.69)$. The two patients who underwent second eye surgery during the study had no evidence of diabetic maculopathy in either eye preoperatively. No maculopathy was observed postoperatively in either eye for the duration of the study period.

Student's paired $t$ test revealed no significant difference in the mean $\mathrm{HbA}_{1} \mathrm{C}$ or duration of diabetes in those patients

Table 7 Analysis of diabetic maculopathy progression with respect to the individual preoperative factors

\begin{tabular}{|c|c|c|c|c|c|c|}
\hline & \multicolumn{3}{|l|}{ Operated eye } & \multicolumn{3}{|c|}{ Non-operated eye } \\
\hline & $\begin{array}{l}\text { DM progressed } \\
(\mathrm{n}=9)\end{array}$ & DM static $(n=41)$ & $\mathrm{p}$ Value & $\begin{array}{l}\text { DM progressed } \\
(\mathrm{n}=7)\end{array}$ & DM static $(n=43)$ & $p$ Value \\
\hline Preoperative mean $\mathrm{HbA}_{1} \mathrm{C}$ (SD) & $8.6 \%(0.6 \%)$ & $8.2 \%(1.6 \%)$ & 0.52 & $8.4 \%(0.8 \%)$ & $8.2 \%(1.6 \%)$ & 0.23 \\
\hline Duration of DM (years) (SD) & $15.4(12.9)$ & $13.4(8.7)$ & 0.57 & $11.9(12.6)$ & $14.0(9.0)$ & 0.58 \\
\hline Pre-existing hypertension $(\mathrm{n}=29$ ) & $6 / 9$ & $23 / 41$ & 0.82 & $4 / 7$ & $25 / 43$ & 0.79 \\
\hline Insulin treatment $(\mathrm{n}=20)$ & $5 / 9$ & $16 / 41$ & 0.61 & $4 / 7$ & $17 / 43$ & 0.34 \\
\hline
\end{tabular}


Table 8 Logistic regression analysis for maculopathy progression

\begin{tabular}{|c|c|c|c|c|}
\hline \multirow[b]{2}{*}{ Variable } & \multicolumn{2}{|l|}{ Operated eye } & \multicolumn{2}{|l|}{ Non-operated eye } \\
\hline & Odds ratio $(95 \% \mathrm{Cl})$ & $\mathrm{p}$ Value & Odds ratio $(95 \% \mathrm{Cl})$ & $\mathrm{p}$ Value \\
\hline Preoperative mean $\mathrm{HbA}_{1} \mathrm{C}$ & $1.0(0.6$ to 1.8$)$ & 0.98 & $1.1(0.5$ to 1.5$)$ & 0.85 \\
\hline Duration of DM & $1.0(0.9$ to 1.1$)$ & 0.63 & $1.0(0.7$ to 1.5$)$ & 0.65 \\
\hline Pre-existing hypertension & 0.9 (0.2 to 5.2$)$ & 0.97 & $3.5(0.1$ to 16$)$ & 0.32 \\
\hline Insulin treatment & $0.8(0.2$ to 4.8$)$ & 0.88 & $4.2(0.8$ to 18.1$)$ & 0.83 \\
\hline
\end{tabular}

whose diabetic maculopathy progressed compared to those patients whose maculopathy did not progress in either the operated or non-operated cohort of eyes (Table 7). There was no significant difference in the number of patients who had pre-existing hypertension, or who required insulin treatment, and maculopathy progression in either the cohort of operated or non-operated eyes (Table 7). Logistic regression analysis failed to reveal a statistically significant relation between any of the preoperative factors and the progression of the diabetic maculopathy in either cohort of eyes postoperatively (Table 8).

\section{DISCUSSION}

Overall, we found that $20 \%$ of eyes undergoing cataract surgery experienced progression of their diabetic retinopathy (DR) in the 12 months following cataract extraction. A review of the literature reveals a wide variation in the percentage of patients who experience retinopathy progression after cataract surgery. While Mittra et al reported that DR progression occurred in just $15 \%$ of patients operated on by a senior surgeon, ${ }^{16}$ other authors have reported retinopathy progression rates of over $70 \% .{ }^{11}$ The large disparity in results of the existing published studies can be explained, at least in part, by inconsistencies in data collection and analysis in the individual studies. The rate of DR progression after cataract surgery is known to be influenced by a number of variables including the severity of the preoperative $\mathrm{DR},{ }^{512}{ }^{16-19}$ the duration of diabetes, ${ }^{5}$ and the adequacy of glycaemic control. ${ }^{5}{ }^{10}$ Direct comparisons between individual studies is therefore only valid if similar cohorts of patients were recruited. Nevertheless, if those studies that have included retinopathy and maculopathy as a single entity are excluded, ${ }^{1120}$ the reported rate of DR progression after cataract surgery in a cohort of patients similar to our own ranges from $15 \%$ to $43 \%{ }^{4-6} 12131516192122$ The rate of retinopathy progression we report is therefore consistent with existing published data.

Our observation that the DR progressed in eight nonoperated eyes during the study is intriguing for it is likely that any retinopathy progression observed in this cohort represented natural disease progression. Although the extrapolation of these data to the cohort of operated eyes is problematic they suggest that much of the retinopathy progression observed in this cohort was not a direct consequence of the surgery. The UKPDS demonstrated that the severity and progression of DR in patients with type 2 diabetes was directly related to glycaemic control. ${ }^{23}$ That the DR progression observed in our study was symmetrical in most cases, occurred more frequently in patients with poor glycaemic control, and had poor glycaemic control as a significant risk factor for its development, suggests instead that much of the retinopathy progression observed in both cohorts of eyes was simply the natural history of the disease. Our data are supported by the results of the one other prospective study that has also examined the relation between glycaemic control and DR progression after cataract surgery. ${ }^{5}$ In this study Henricsson et al prospectively followed the diabetic retinopathy of both the operated and non-operated eye of 35 patients who underwent monocular cataract surgery. They too reported a similar rate of
DR progression in both the operated and non-operated eye, and also found that patients whose DR progressed had a significantly higher mean $\mathrm{HbA}_{1} \mathrm{C}$ than those patients whose DR did not progress. ${ }^{5}$

Our finding that cataract surgery was not associated with an accelerated rate of retinopathy progression postoperatively appears to contradict much of the existing published data. It is tempting to postulate that this disparity may simply reflect changes in surgical technique over the past decade as much of the existing data relates to extracapsular rather than phacoemulsification cataract extraction. However, a recent prospective controlled study reported similar rates of retinopathy progression after both surgical techniques. ${ }^{21}$ Unfortunately, both the numbers participating in this study, and the difference in the reported rates of retinopathy progression after each technique were small. This study therefore lacks the power to provide the definitive answer to whether one technique causes less retinopathy progression than the other. Nevertheless, these and other data ${ }^{613162224}$ suggest that any differences between the two techniques may not be marked. An alternative answer as to why our findings contradict existing data is therefore required.

A systematic review of the literature reveals that much of the existing data relating to retinopathy progression after all types of cataract surgery have been derived from retrospective case note reviews. In some cases these studies have been uncontrolled $^{1622} 25$ and where controlled studies exist the control group often comprised a matched population of patients with diabetes who did not undergo surgery ${ }^{40}$ or a population of patients without diabetes undergoing surgery. ${ }^{3}$ The retrospective analysis of data to elucidate the natural history of any progressive condition has fundamental methodological weaknesses. Arguably, a more reliable way of controlling such retrospective data would be to compare retinopathy progression in both the operated and fellow eye of the same patient after monocular surgery. When the results of studies which employed this method are reviewed, the argument that uncomplicated cataract surgery is directly responsible for retinopathy progression is less convincing. ${ }^{12}{ }^{15}{ }^{26}$ The disparity between our findings and much of the existing data may therefore simply reflect methodological differences in data collection and analysis. A review of the two case controlled trials that examined the retinopathy progression of both the operated and non-operated fellow eyes after cataract surgery support our findings that where progression occurred, it generally did so in both eyes simultaneously. ${ }^{56}$

The distinction between diabetic maculopathy and pseudophakic "Irvine Gass" cystoid macular oedema in postoperative cataract patients remains controversial. The first prospective controlled trial which evaluated the natural history of macular oedema in diabetics after cataract surgery was reported by Pollack et al. ${ }^{14}$ They found that although 22 of the 44 patients in their study developed postoperative macular oedema, this settled without recourse to laser treatment in 11. Only five patients required laser treatment for clinically significant oedema which met the ETDRS criteria, findings which suggested that the early laser treatment of all diabetics with postoperative macular oedema was unnecessary. Benson later 
proposed that laser photocoagulation of postoperative macular oedema in diabetic patients should therefore be delayed for up to 6 months to allow the Irvine Gass component to resolve before applying treatment. ${ }^{18}$ The protocol we employed for dealing with postoperative macular oedema was therefore based on the published data available to us at the time this study was designed. Our approach to postoperative macular oedema has since been vindicated by other data. ${ }^{27}$

Overall, we found that only eight out of the 13 operated eyes that developed macular oedema after cataract surgery had clinically significant diabetic macular oedema which required laser treatment. This finding supports the conclusions of previous studies which have suggested that postoperative macular oedema can follow a benign course in a significant number of patients with diabetes. ${ }^{142127}$ One surprising finding of our trial was that progressive diabetic maculopathy occurred simultaneously in both the operated and non-operated eye in five patients. The extrapolation of these data to the cohort of operated eyes is difficult. Nevertheless, it does suggest that when CSMO developed postoperatively in the operated eye it was not, at least in the majority of cases, a direct consequence of the surgery but was simply the natural history of the disease. To date there have been no other prospective controlled trials which have examined the course of diabetic maculopathy in both eyes after monocular surgery and it is therefore impossible to corroborate these findings. Our findings are however supported by the ETDRS study report number 25 which concluded that there was no statistically significant long term increased risk of macular oedema after lens extraction. ${ }^{26}$

One potential concern about deferring laser photocoagulation therapy for postoperative macular oedema is that chronic macular oedema may have compromised the visual outcome for some patients. As yet no prospective randomised trial has been conducted to answer this question. However, we and others ${ }^{1427}$ have found that even macular oedema that is not typical pseudophakic cystoid macular oedema can settle spontaneously in some patients. The early application of laser treatment for postoperative macula oedema in patients with diabetes would therefore mean over treating some patients. The proportion of eyes in our study with a postoperative visual acuity of 6/12 or better compares favourably with the existing data. ${ }^{13} 162426$ In line with previous studies we also found that pre-existing maculopathy, ${ }^{31321222728}$ or age related macular degeneration, ${ }^{3}$ were the principal determinants of a poor visual outcome. As our visual acuity outcome data compare favourably with that reported by existing studies we feel confident that our strategy of deferring laser photocoagulation treatment for postoperative macular oedema was not detrimental to patients' visual outcome. Of equal importance is that the two patients whose macular oedema settled spontaneously did not receive unnecessary laser treatment.

As our study was only powered to detect a threefold increased risk of retinopathy and maculopathy progression after surgery it cannot provide the definitive answer to the question of whether cataract surgery is, or is not, associated with accelerated disease progression postoperatively. Nevertheless, the fact that retinopathy and maculopathy progression was very often symmetrical and was, in the case of retinopathy progression, associated with poor glycaemic control, does suggest that much of the progression we observed simply represented the natural history of the disease. While our findings have to be interpreted with caution we believe that they may have important implications for the future care of diabetic patients with cataracts. Previously, because of the perceived threat of rapidly progressive postoperative diabetic retinopathy and maculopathy, authors recommended that cataract extraction should not be conducted on patients with diabetes until the vision deteriorated to at least $6 / 36 .{ }^{14}$ We believe this argument is no longer valid. Our data and those of others suggest that cataract surgery has minimal impact on the postoperative course of an eye's diabetic retinopathy. Furthermore, our findings also suggest that the impact of cataract surgery on the incidence of postoperative CSMO has been overestimated. There is now increasing evidence that unrecognised CSMO at the time of surgery poses the greatest risk to postoperative visual outcome, a finding which has prompted Dowler et al to recommend that cataract surgery now be conducted on diabetics early to avoid the risk of CSMO going unrecognised at the time of surgery. ${ }^{21}$ Our data support this proposal.

\section{CONCLUSION}

Our findings suggest that uncomplicated phacoemulsification cataract surgery may not be responsible for an accelerated rate of DR progression postoperatively. Instead, our findings suggest that any DR progression that does occur postoperatively may simply represent the natural history of the disease. We found that although macular oedema was common after cataract surgery it often followed a benign course and in many cases was accompanied by similar changes in the fellow eye. Overall, our findings suggest that although uncomplicated phacoemulsification cataract surgery may be associated with progressive diabetic maculopathy in many patients the development of CSMO postoperatively probably represents natural disease progression, rather than being a direct effect of the surgery.

\section{ACKNOWLEDGEMENTS}

We would like to thank Dr R Taylor of the statistical services unit in the department of probability and statistics, University of Sheffield for all her assistance in the statistical analysis of this study.

Presented as a poster at the 2001 annual congress of the Royal College of Ophthalmologists.

\section{Authors' affiliations}

D Squirrell, J Bush, S Winder, JF Talbot, Department of

Ophthalmology, Royal Hallamshire Hospital, Sheffield S10 2RX, UK

R Bhola, University Department of Ophthalmology and Orthoptics, Floor

O, Royal Hallamshire Hospital, Sheffied S10 2JF, UK

\section{REFERENCES}

1 Hamilton AMP, Ulbig MW, Polkinghorne P, eds. Epidemiology of diabetic retinopathy. In: Management of diabetic retinopathy. London: BM Publishing Group, 1996:1-15

2 Royal College of Ophthalmologists. Guidelines for diabetic retinopathy London: RCO, 1997.

3 Cunliffe IA, Flanagan DW, George NDL, et al. Extra capsular cataract surgery with lens implantation in diabetics with and without proliferative retinopathy. Br J Ophthalmol 1991;75:9-12

4 Pollack A, Dotan S, Oliver M. Progression of diabetic retinopathy after cataract extraction. Br J Ophthamol 1991;75:547-51

5 Henricsson $M$, Heiil A, Janzon L. Diabetic retinopathy before and after cataract surgery. Br J Ophthamol 1996;80:789-93.

6 Wagner T, Knaflic D, Rauber M, et al. Influence of cataract surgery on the diabetic eye:a prospective study. German J Ophthalmol 1996;5:79-83.

7 ETDRS Report No 10. Grading diabetic retinopathy from stereoscopic color fundus photographs - an extension of the modified Airlie house classification. Ophthalmology 1991;98:786-806

8 Early Treatment Diabetic Retinopathy Study Group Photocoagulation for diabetic macular oedema. Arch Ophthalmol 1985; 103:1796-806.

9 Gass JDM, Norton EWD. Cystoid macular edema and papilloedema following cataract extraction: a fluorescein funduscopic and angiographic study. Arch Ophthalmol 1966;76:646-61.

10 Kodama T, Hayasaka S, Setogawa. Plasma glucose levels, postoperative complications, and progression of retinopathy in diabetic patients undergoing intraocular lens implantation. Graefes Arch Clin Exp Ophthalmol 1993;231:439-43.

11 Jaffe GJ, Burton TC, Kuhn E, et al. Progression of non-proliferative diabetic retinopathy and visual outcome after extracapsular cataract extraction and intraocular lens implantation. Am J Ophthalmol 1992; 1 14:448-56.

12 Pollack A, Leiba H, Bukelman A, et al. The course of diabetic retinopathy following cataract surgery in eyes previously treated by laser photocoagulation. Br J Ophthalmol 1992;76:228-31.

13 Ancliffe RJ, Poulson A, Flanagan DW. Phacoemulsification in diabetics. Eye 1996;10:737-41 
14 Pollack A, Leiba $\mathrm{H}$, Bukelman A, et al. Cystoid macular oedema following cataract extraction in patients with diabetes. $\mathrm{Br} J$ Ophthalmol 1992;76:221-4.

15 Sebestyen JG. Intraocular lenses and diabetes mellitus. Am J Ophthalmol 1986;101:425-8.

16 Mittra RA, Borrillo JL, Dev S, et al. Retinopathy progression and visual outcomes after phacoemulsification in patients with diabetes mellitus. Arch Ophthalmol 2000;118:912-17.

17 Aiello LM, Wand M, Liang G. Neovascular glaucoma and vitreous hemorrhage following cataract surgery in patients with diabetes mellitus. Ophthalmology 1983;90:814-20.

18 Benson WE. Cataract surgery and diabetic retinopathy. Curr Opin Ophthalmol 1992:3:396-400.

19 Hykin PG, Gregson MC, Stevens JD, et al. Extracapsular cataract extraction in proliferative diabetic retinopathy. Ophthalmology 1993;100:394-9.

20 Schatz H, Atienza D, McDonald R, et al. Severe diabetic retinopathy after cataract surgery. Am J Ophthalmol 1994;117:314-21.

21 Dowler JGF, Hykin PG, Hamilton AMP. Phacoemulsification versus extracapsular cataract extraction in patients with diabetes. Ophthalmology 2000;107:457-62.
22 Chiu D, Meusemann RA, Kaufman DV, et al. Visual outcome and progression of retinopathy after cataract surgery in diabetic patients. Aust NZ J Ophthalmol 1998;26:129-33.

23 Kohner E, Aldington SJ, Stratton IM, et al. United Kingdom Prospective Diabetes study, 30. Diabetic retinopathy at diagnosis of non insulin dependent diabetes mellitus and associated risk factors. Arch Ophthalmol 1998:116:297-303

24 Raskauskas PA, Walker JP, Wing GL, et al. Small incision cataract surgery and placement of posterior chamber intraocular lenses in patients with diabetic retinopathy. Ophthalmic Surg Lasers 1999;30:6-11.

25 Benson WE, Brown GC, Tasman W, et al. Extracapsular catarac extraction with placement of a posterior chamber lens in patients with diabetic retinopathy. Ophthalmology 1993;100:730-8.

26 Chew E, Benson WE, Remaley N, et al. Results after lens extraction in patients with diabetic retinopathy; ETDRS report no 25. Arch Ophthalmol 1999;117:1600-6.

27 Dowler JGF, Sehmi KS, Hykin PG, et al. The natural history of macular edema after cataract surgery in diabetes. Ophthalmology 1999:106:663-8

28 Dowler JGF, Hykin PG, Lightman SL, et al. Visual acuity following extracapsular cataract extraction in diabetes: a meta-analysis. Eye 1995;9:313-17.

\section{Rapid responses}

Letters on the following British Journal of Ophthalmology papers have been published recently as rapid responses on the BJO website. To read these letters visit www.bjophthalmol.com and click on "Read eletters"

S Amin, M Minihan, S Lesnik-Oberstein, C Carr. A new technique for delivering subTenon's anaesthesia in ophthalmic surgery. Br J Ophthalmol 2002;86:119-120.

N Morlet, D Minassian, J Dart. Astigmatism and the analysis of its surgical correction. Br J Ophthalmol 2001;85:1127-1138.

$\mathrm{L} X \mathrm{ie}, \mathrm{X}$ Dong, W Shi. Treatment of fungal keratitis by penetrating keratoplasty. $\mathrm{Br}$ J Ophthalmol 2001;85:1070-1074.

GE al Araba, N Tawfika, R El Gendyb, W Anwarc, P Courtright. The burden of trachoma in the rural Nile Delta of Egypt: a survey of Menofiya governorate. $\mathrm{Br} J$ Ophthalmol 2001;85:1406-1410.

P Riordan-Eva, K Landau, J O'Day. Temporal artery biopsy in the management of giant cell arteritis with neuro-ophthalmic complications. $\mathrm{Br} J$ Ophthalmol 2001;85:1248-1251.

If you would like to post an electronic response to these or any other articles published in the journal, please go to the website, access the article in which you are interested, and click on "eletters: Submit a response to this article" in the box in the top right hand corner. 